\title{
Feasibility of the iPad as a hub for smart house technology in the elderly; effects of cognition, self-efficacy, and technology experience
}

This article was published in the following Dove Press journal:

Journal of Multidisciplinary Healthcare

27 November 2012

Number of times this article has been viewed

\author{
Hilde Alvseike' \\ Kolbjørn Brønnick ${ }^{2,3}$ \\ 'The Norwegian Centre for \\ Movement Disorders, ${ }^{2}$ Regional \\ Centre for Clinical Research in \\ Psychosis, Division of Psychiatry, \\ Stavanger University Hospital, \\ Stavanger, Norway; ${ }^{3}$ The Reading \\ Centre, University of Stavanger, \\ Stavanger, Norway
}

\begin{abstract}
Smart house technology using tablet computers may help older people to master activities of daily living by making it easier to perform daily tasks like controlling lights and indoor temperature throughout the house with a few keystrokes. The aim of this study was to investigate the impact of age, cognition, self-efficacy, and technology experience on the ability of older people to perceive and use iPad tablet computers for this purpose. Twenty-eight participants were interviewed using a structured interview guide and questionnaires, and a practical test of how to use the iPad was performed. The Mini-Mental State Examination (MMSE) was used to assess cognition. Cognitive deficits and low self-efficacy significantly reduced the ability of the subjects to use the smart house technology and to perceive the smart house technology service as provided. Age was unrelated to the outcome variables. Finally, technology experience had an effect on technology perception. If further research supports these findings, it should influence smart-house implementation in an elderly population, raising awareness of usability problems in older people with low self-efficacy and cognitive problems.
\end{abstract}

Keywords: smart house technology, iPad, cognition, self-efficacy, technology experience, elderly

\section{Introduction}

\section{Background}

There is an ongoing shift in demographics throughout the industrialized world, with the proportion of elderly people increasing. Towards 2060, the proportion of elderly in Norway will double compared with the working age population. ${ }^{1}$

As a corollary to this, the costs associated with home care service and nursing home placement in Norway increased by $131 \%$ in the years from 1998 to $2008^{2}$ and reached an estimated cost of 45.3 billion Norwegian kroner in 2006. Nursing home placement is also associated with a lower quality of life and with rapid deterioration of function. ${ }^{3}$ Enabling older people to stay for a longer time in their own homes is economically beneficial and will lead to better quality of life for older individuals.

Smart house technology, defined as automated or intelligent technological solutions installed in the home to monitor, alert, and perform actions according to selected criteria, ${ }^{4}$ eg, light and temperature control using an iPad, has been proposed as a solution for enabling older people to live independently for a longer time in their own homes. ${ }^{5}$ The main aim of offering this new technology is to facilitate activities of daily living (ADL) by narrowing the gap between a person's capacity and her environment. ${ }^{6}$

It is not clear whether smart house technology is feasible in the general older population, due to both competence and acceptance issues. Selwyn and colleagues 
investigated a sample of 362 older subjects and found a more than 50\% lower usage of computers and Internet than among people between 20 and 40 years of age, with only $22 \%$ of the older subjects having used a computer the last 12 months before the survey. ${ }^{7}$ Further, access to computers and Internet was much lower. The main reasons stated for not using a computer were "no interest", "too old", and "no use". However, in Norway, the national agency, Statistics Norway, sampled 2000 subjects and found a much higher prevalence of PC usage (67\% of those aged above 65 years had used a PC the last 3 months $)^{8}$ and that there has been a large increase in PC use among the elderly since 2003. Hence, older people are increasingly familiar with computers. However, there is evidence that older people have greater difficulty than others in using computers and technology in general, ${ }^{9}$ and that demographic variables and intellectual abilities influence older adults' ability to use computers and other technologies. ${ }^{9}$

The latter finding is highly relevant in the present context, as older people in need of home care service often have cognitive impairments. ${ }^{10}$ This represents a challenge, as cognitive impairment has been shown to reduce the ability to use every-day technology ${ }^{11}$ and to increase the perception of difficulty in using technology. ${ }^{12}$ Other factors, like technology self-efficacy and technology experience may also affect and moderate the acceptance and use of technology. ${ }^{9}$ Self-efficacy refers to one's perceived belief with regard to coping and possibility for success in action. ${ }^{13}$ Technology experience is probably also a central factor, as previous experience with electronic devices may lessen the need for accommodation to new technology. Feasibility of using smart house technology in the older population may be negatively affected by factors that are related to technology use in general in the older population, and hence there may be barriers related to cognitive impairment, self-efficacy, and experience. ${ }^{9}$

In the present study, we report findings related to the above-mentioned factors from a pilot project in southwestern Norway. We investigated the impact of cognition, technology self-efficacy, and technology experience on the ability to perceive and use the smart house technology aspect of this project, which relied heavily on the use of the iPad or tablet computers as control hubs. iPads and tablet computers represent a radical innovation with regard to user interface as compared with older computers by using a touchscreen interface rather than physical buttons and keyboards. We have little knowledge about how older people perceive this technology and how they may learn to use it and cope with it. There are a few published reports showing that elderly like touchscreen interfaces and are in general able to use them, ${ }^{14,15}$ but we have not found research showing the impact of cognition or self-efficacy on iPad usage among the elderly.

We predicted that cognition would exert an effect on technology perception and ability to use the smart house technology. Further, we also predicted that technology experience would impact perception and ability to use the technology. We predicted that technology self-efficacy would affect the ability to use the smart house technology and finally, we hypothesized that age would impact both ability to use and to perceive the technology, but that this effect is moderated by cognition.

\section{Methods}

\section{The project}

This project was a pilot project and a collaboration between Stavanger University, home care service in two municipalities, Stavanger University Hospital, and industrial companies where the aim was to develop and introduce smart house technology to the elderly, gain experience, and investigate whether this measures could make it easier and safer for older people to live independently for a longer time in their own homes. The project was scheduled to last 16 months in total; 4 months for planning, 9 months for implementation including installation and use of the technology, and 3 months for evaluation of the project. When this evaluation took place, the participants had had the opportunity to use the smart house technology for about 4-5 months.

\section{Subjects, recruitment procedures, and inclusion criteria}

All subjects were ethnic Norwegians living in southwestern Norway, situated around the Stavanger municipality. The participants were volunteers recruited from a networking club for the elderly (Skipper Worse in Stavanger) and from the home care service in two municipalities (Stavanger and Randaberg).

Skipper Worse is a social networking place for seniors aged over 60 years. The project group disseminated information about the project at the club. The ones who wanted to participate, signed up and were selected for participation based partly on technical criteria related to their home situation, such as fiber optic cable or mobile phone Internet access (3G).

Individuals with presumed cognitive impairment were recruited by the home care service from Randaberg County (10,000 inhabitants). However, we did not have access to any 
formal medical information regarding diagnoses. Hence, the inclusion criteria were informal and based on the judgment of the home care service. The aim was to include seven such subjects. The participants should be living in their own homes, be able to manage basic ADL on their own, but receive some help and support from home care service.

From the home care service in Stavanger, individuals over 70 years of age with a physical disability that led to problems with movement, were recruited. This could range from using a walker to having more severe movement disability that led to need for assistance in most daily activities. The aim was to include seven subjects. They should all live in their own homes and receive help from home care service. Coinhabitant spouses of the participants were also included in the project.

Participation in this project was voluntary and required a written consent before participation. Before initiation of this study, ethical evaluation was gathered from the regional medical ethical commitee according to the Declaration of Helsinki.

All of the data used in this study were collected by the author (HA) during a home visit to each of the participants. The interviews were based on questionnaires and a structured interview guide as well as a practical test of how to use the iPad. All data were collected during a period of 1 month, January to February, 2012.

\section{Assessment and instruments}

General information was collected, defined as the participants' age, sex, education and work experience in the last 5 years before retirement.

Information technology and computer experience was assessed by asking 16 questions concerning experience with computers, cellphones and home appliances, such as: "Do you own a PC?", "How many cellphones have you owned?", "How often do you use your cellphone for calling?" etc. The interview guide provided possible answers such as "never, rarely, monthly, weekly, daily" etc, and "Yes/No".

The self-efficacy items were designed according to Bandura's guidelines for designing self-efficacy measures, "Guide for Constructing Self-efficacy Scales." "16 We asked seven questions such as "How well can you use a computer?" and "How well can you learn to use a new mobile phone". The participants were asked to grade their own efficacy on a scale from 1 to 7, where 1 indicated "Cannot do" and 7 "Can do very well". Bandura recommends that self-efficacy scales are tailormade for the context in which self-efficacy is investigated, ${ }^{16}$ hence our scale is not validated by previous research, but the validity depends on adherence to the principles recommended by Bandura. It should be noted that we did not explicitly use the wording "confidence" in the ability to perform a given activity, as recommended by Bandura. Nevertheless, Cronbach's alpha for the total scale was 0.83 , indicating that the scale as a whole was reliable. Further, the Pearson correlation coefficient between the "can use" questions and "can learn to use" questions was 0.777 . Taken together, this indicates that the scale probably was valid and worked well as a reliable measure of self-efficacy.

\section{Technology perception and practical testing of iPad use}

First, the participants were asked to list in their own words all the technologies and services they had received, what purpose it served, and how it worked. Further a practical test where the participants demonstrated how to control "household-functions" such as indoor temperature and lighting by using iPad, was performed. This test was then rated by the interviewer as "Can"/“Cannot" perform the requested action. "Can" was rated when the participant immediately performed the requested action, but a little hesitation and uncertainty was accepted. "Cannot" was rated when the participant could not perform the requested action upon request.

\section{Cognitive impairment}

The Mini-Mental Status Examination (MMSE) ${ }^{17}$ was used as a measure of cognitive global performance.

\section{Statistics and data analysis}

The scale for technology usage was calculated by converting all items regarding previous and current technology usage (PC and mobile phone(s)) to standardized $z$-scores and calculating the average $z$-score.

Distribution of the variables was inspected using histograms and it was decided to use $t$-tests for independent samples for investigating differences between means, assuming equal variances in the groups whenever Levene's test for equality of variances was nonsignificant. One-tailed $P$-values are reported, as there were specific hypotheses regarding direction of differences. Effect sizes are reported using Cohen's d, where $<0.3$ is considered small, 0.5 medium, and $>0.8$ a large effect size. ${ }^{18}$

In order to identify optimal cut-off points with regard to MMSE as related to technology perception and ability to use the iPad for smart house control, we performed a receiveroperating characteristic (ROC)-curve analysis, reporting the 
sensitivity and specificity for the chosen cut-off as well as area under the curve.

Categorical variables were tested for statistical differences using Fisher's exact test.

The computer program, $\mathrm{G}^{*}$ Power $3,{ }^{19}$ was used to assess post-hoc achieved power in case of nonsignificant results. All other statistics were calculated using SPSS software (v 18.03; IBM, Armonk, NY).

\section{Results}

In total, 28 elderly were included. Stavanger home care service recruited six subjects of whom three had a participating spouse. Randaberg home care service recruited six subjects of whom two had a participating spouse. Five were recruited directly from Skipper Worse, of whom four had participating spouses. Finally, one couple was recruited ad hoc by one of the project participants. Due to the lack of formal inclusion criteria, the sample is presented and analyzed as a bloc, and not analyzed based on which recruitment group the subjects came from. Demographics and background variables are presented in Table 1. Subject technology access is reported in Table 2.

\section{Technology perception}

In Table 3, we report technology perception, defined as reporting the reception of a service or technology that the subject actually had received.

Testing our hypotheses with regard to the iPad, MMSE scores in individuals who did not perceive that they had been given an iPad $(\mathrm{N}=8$, mean $=22.25$, standard deviation [SD] $=3.37$ ), were lower than for those who did perceive it $(\mathrm{N}=20$, mean $=27.60, \mathrm{SD}=2.03), P<0.001$, Cohen's $\mathrm{d}=1.92$. Thus, the impact of cognition on technology perception was very large, as shown by the very large effect size. ${ }^{18}$

Technology experience was also lower $(\mathrm{N}=8$, mean $=-0.47, \mathrm{SD}=0.48)$ in the group who did not report perception of the iPad than in those who did perceive it $(\mathrm{N}=20$, mean $=0.18, \mathrm{SD}=0.67), P=0.01$, Cohen's $\mathrm{d}=1.13$.

Table I Description of the samples

\begin{tabular}{ll}
\hline $\mathrm{N}$ & 28 \\
Sex: $M / \mathrm{F}$ & $\mathrm{I} / \mathrm{I} 7$ \\
Age: mean (SD) & $78.5(9.7)$ \\
Education years: mean (SD) & $12.4(3.7)$ \\
Coinhabitant: $\mathrm{N}$ & 20 \\
MMSE: mean (SD) & $26.0(3.4)$ \\
\hline A &
\end{tabular}

Abbreviations: MMSE, Mini-Mental State Examination; M, male; F, female; $\mathrm{SD}$, standard deviation; $\mathrm{N}$, number of subjects.
Table 2 Technology access/experience

\begin{tabular}{ll}
\hline PC access: yes/N (\%) & $13 / 28(46 \%)$ \\
Own mobile phone: yes/N (\%) & $23 / 28(82 \%)$ \\
Own iPhone: yes/N (\%) & $4 / 28(14 \%)$ \\
Owned iPad previously: yes/N (\%) & $0 / 28(0 \%)$ \\
Own iPod touch: yes/N (\%) & $1 / 28(4 \%)$
\end{tabular}

Abbreviations: N, number of subjects; PC, personal computer.

Age was not different in the group who did not report perceiving the iPad $(\mathrm{N}=8$, mean $=80.7, \mathrm{SD}=11.7)$ versus those who did $(\mathrm{N}=20$, mean $=77.6, \mathrm{SD}=9.0)$, $P=0.45$.

A ROC curve analysis (Figure 1) identified a cut-off of 25 points on the MMSE as optimal for distinguishing between those who perceived versus did not perceive receiving an iPad for smart house control. The resulting sensitivity was $90 \%$ and the specificity was $75 \%$ (area under the curve $=0.922$; $P<0.001)$.

\section{Ability to use smart house technology}

In Table 4, we present the ability of the subjects to use the smart house technology they had access to. All subjects had access to iPad control of home lighting, hence this was chosen for statistical analysis in order to avoid missing values. Further, control of light is an activity that normally is performed several times a day, making this a valid measure of iPad smart house control.

We found that five of $11(45 \%)$ men were able to use this function, versus seven of 17 (41\%) women. These proportions were not significantly different, as assessed with Fisher's exact test $(P=0.56)$. MMSE in individuals who were unable to use the iPad to control lights $(\mathrm{N}=16$, mean $=24.68, \mathrm{SD}=3.70$ ) was lower than in those who were able $(\mathrm{N}=12$, mean $=27.91, \mathrm{SD}=2.02), P=0.006$, Cohen's $\mathrm{d}=1.08$. This is a large effect-size. ${ }^{18}$

Age was not different in the group who were unable to use the iPad for light control $(\mathrm{N}=16$, mean $=80.2, \mathrm{SD}=11.1)$ versus in those who were able $(\mathrm{N}=12$, mean $=76.1$, $\mathrm{SD}=7.3), P=0.28$.

A ROC curve analysis (Figure 2) identified a cut-off of 25 points on the MMSE as optimal for distinguishing between

Table 3 Perception of received technology

\begin{tabular}{ll}
\hline iPad: yes/no (\%) & $20 / 28(71 \%)$ \\
Door camera: yes/N (\%) & $20 / 26(77 \%)$ \\
Theft alarm: yes/N (\%) & $19 / 25(76 \%)$ \\
Fire alarm: yes/N (\%) & $19 / 27(70 \%)$ \\
Video telephone: yes/N (\%) & $11 / 24(45 \%)$ \\
\hline
\end{tabular}

Abbreviation: $\mathrm{N}$, number of subjects who actually had the technology. 


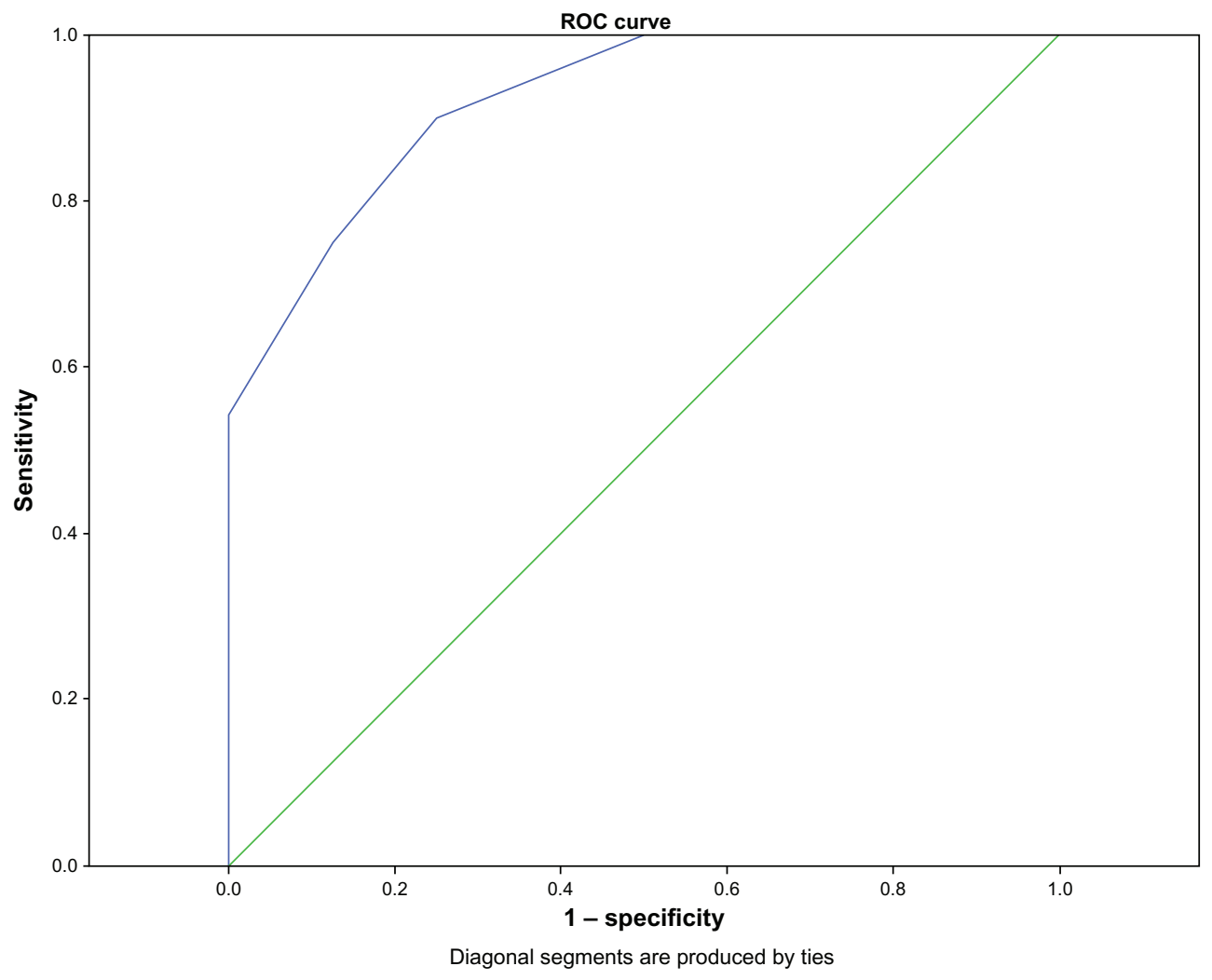

Figure I Receiver-operating characteristic (ROC) curve analysis for perception of the iPad for smart house control.

those who were able to use the iPad for smart house control of lights versus those who were unable. The resulting sensitivity was $100 \%$ and the specificity was $50 \%$ (area under the curve $=0.794 ; P=0.009$ ).

Technology self-efficacy was lower in the subjects who were unable to use the iPad to control lights $(\mathrm{N}=16$, mean $=3.81, \mathrm{SD}=1.45)$ versus those who were able $(\mathrm{N}=12$, mean $=5.02, \mathrm{SD}=0.53), P=0.003$, Cohen's $\mathrm{d}=1.11$. This is a large effect-size. ${ }^{18}$

There was no difference in technology experience between those who did and did not manage to use the iPad to control lights $(P=0.099$, Cohen's $d=0.62)$. A post hoc power analysis using Gpower* $3^{19}$ showed that the achieved power to detect a Cohen's d of 0.8 (a large effect size), was $65 \%$. Hence, this result could be due to lack of statistical power to detect a difference. The same applies to age.

Table 4 Ability to use iPad functionality

\begin{tabular}{ll}
\hline iPad light control: yes/N (\%) & $12 / 28(42 \%)$ \\
iPad heat control: yes/N (\%) & $8 / 20(40 \%)$ \\
iPad curtain control: yes/N (\%) & $4 / 7(57 \%)$ \\
iPad TV control: yes/N (\%) & $0 / 3(0 \%)$ \\
\hline
\end{tabular}

Abbreviation: $\mathrm{N}$, number of subjects who actually had the technology.

\section{Discussion}

Cognition had a large impact on the ability of elderly subjects to use iPads as control hubs of smart house technology and to perceive that the iPad was given as a hub for smart house control. Further, self-efficacy was also strongly related to the ability of elderly people to use iPads to control smart house technology. Technology experience had an effect on technology perception, but not on the ability to use the technology. Finally, there was no effect of age as related to both usage and perception of the technology.

An implication of our findings is that those elderly people who may need smart house technology the most, the cognitively impaired, are those who have the least ability to use it. This a serious issue, especially considering the fact that the major cause of cognitive deficit in older people is Alzheimer's disease, causing at least $70 \%$ of all new cases of dementia. ${ }^{20}$

The main cognitive deficit in Alzheimer's disease is in episodic memory, precisely the type of memory needed for learning and remembering new information. For individuals with this kind of memory deficit, the existence of, purpose of and usage of smart house technology may not be learned initially. If learned, it may be forgotten, even in subjects who do not suffer from severe dementia. As Alzheimer's and other 


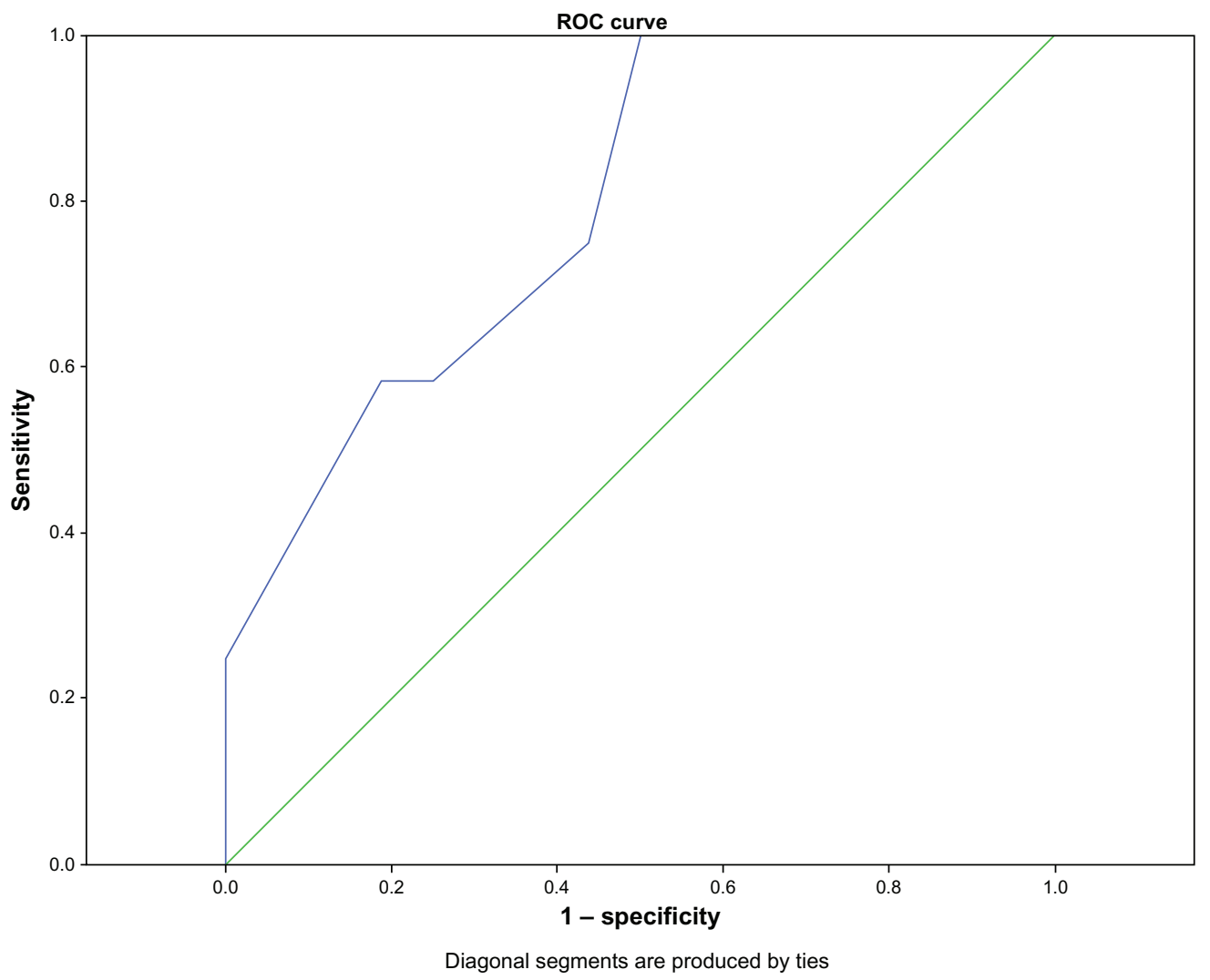

Figure 2 Receiver-operating characteristic (ROC) curve analysis for ability to use an iPad for smart house control of lights.

neurodegenerative diseases progress, cognition and memory worsen. Deficits in episodic memory may also account for the findings related to technology perception. The problem may not be lack of perception, but rather memory regarding the projects and its technologies and services. We do not have data that can decide this issue. Nevertheless, our findings are in accordance with earlier research that has showed that cognitive impairment in the elderly reduces the ability to use technology. ${ }^{11}$

Self-efficacy was also related to ability to use the technology. The level of self-efficacy may affect the selection of behavior such as the effort invested in using and learning the technology, as well as thoughts and emotional reactions during technology usage. ${ }^{21}$ Importantly, self-efficacy is a parameter that can be enhanced by using several strategies such as using role models whom the subjects can identify with, like other seniors in similar circumstances. ${ }^{13}$ The presence of peer role models could strengthen confidence and thus increase motivation for action. ${ }^{13}$ In this study, training was provided by young, professional technicians and this may have affected the adoption of the technology as well as the selfefficacy, given that the participants probably had difficulties identifying themselves with a young technical "expert". In addition, the technicians did not have any teaching or training experience and this may also have influenced their ability to understand the needs of older people. Finally, self-efficacy may be increased by social persuasions such as support and encourage from caregivers and also training managers.

However, self-efficacy may not only affect technology use, but also be an end result of interaction with technology. Experiencing success and mastery raises self-efficacy and failure lowers it. ${ }^{13} \mathrm{~A}$ successful experience in the past will increase self-efficacy and the subject can be motivated to act. Thus, the observation that self-efficacy was related to ability to use technology is possibly also an end result of a process where the individual has failed to use and understand the technology.

Technology experience was hypothesized to be a predictor for ability to use smart house technology. This study did not find this. Nor did we reveal any significant differences related to gender in the ability to use the iPad for controlling smart house functions. However, negative findings remain inconclusive due to lack of statistical power, and this must be followed up in future research with larger samples.

Age in itself was not an obstacle to the introduction of smart house technology in this study. Higher age is associated with a higher risk of dementia, but in this case, the effect is mediated by cognition and one need probably not be 
concerned with age as an independent phenomena. However, the same problem with statistical power as mentioned above applies here also. Hence, this finding must be viewed with caution.

\section{Strengths of the study}

This is probably the first investigation on the impact of cognition on the ability of elderly people to use an iPad to control smart house technology and is one of the very few studies with actual user testing of older people's ability to use smart house technology. Further, all examinations were conducted by the same experienced research nurse and the examinations were interview based, minimizing misunderstandings of questions. Finally, the practical testing of ability to use an iPad, represents a novel approach with very high ecological validity.

\section{Limitations of the study}

The number of subjects studied in this study is relatively small. This means that lack of differences such as for age and technology experience may be an artifact of low statistical power. The absence of clearly defined inclusion and exclusion criteria are another potential limitation and as such, the studied sample may not be representative for the general elderly population. Finally, the MMSE is a very limited cognitive test, precluding the analysis of specific cognitive domains such as memory and attention.

In future research, one should employ clear selection criteria, recruitment of a representative sample, and more structured and individualized training strategies, ie, training performed by educated personal and one may also take into account role model learning by peers. Finally, better cognitive tests should be used.

\section{Conclusion}

Cognitive impairment is a challenge when introducing new technology to the elderly. In practical terms, a cut-off at 25 points on the MMSE was optimal in the present study for distinguishing between those who were able versus unable to use the iPad for smart-house control, but further research must follow up to investigate generalizability.

Self-efficacy is a promising approach for facilitating the adoption of smart house technology, as it could be enhanced for instance by providing better training using role models and support groups. Old age may not be a hindrance for smart house technology use and perception.

\section{Disclosure}

The authors report no conflicts of interest in this work.

\section{References}

1. St.meld.nr.9. Perspektivmeldingen 2009. Oslo, Norway: Finansdepartementet; 2009. [Long-Term Perspectives for the Norwegian Economy]. Available in English at http://www.regjeringen.no/en/ $\mathrm{dep} /$ fin/press-center/press-releases/2009/long-term-perspectivesfor-the-norwegian.html?id=542381.

2. Garasen H, Magnussen J, Windspoll R, Johnsen R. Elderly patients in hospital or in an intermediate nursing home department - cost analysis. Tidsskr Nor Laegeforen. 2008;128(3):283-285.

3. Scocco P, Rapattoni M, Fantoni G. Nursing home institutionalization: a source of eustress or distress for the elderly? Int J Geriatr Psychiatry. 2006;21(3):281-287.

4. Stefanov DH, Zeungnam B, Won-Chul B. The smart house for older persons and persons with physical disabilities: structure, technology arrangements, and perspectives. Neural Systems and Rehabilitation Engineering, IEEE Transactions on. 2004;12(2):228-250.

5. NOU2011:11. Innovasjon i omsorg. Oslo, Norway: Helse-og omsorgsdepartementet; 2011. [Innovation in the Care services]. Available in English at http://www.regjeringen.no/pages/37990512/PDFS/ NOU201120110011000EN_PDFS.pdf

6. McCreadie C, Tinker A. The acceptibility of assistive technology to older people. Ageing and Society. 2005;25:91-110.

7. Selwyn N, Gorard S, Furlong J, Madden L. Older adults' use of information and communications technology in everyday life. Ageing and Society. 2003;23(05):561-582.

8. Statistics Norway. IKT i husholdningene. 2010. Available from: http://www.ssb.no/emner/10/03/ikthus/arkiv/tab-2010-09-24-03.html. Accessed on November 10, 2012.

9. Czaja SJ, Charness N, Fisk AD, et al. Factors predicting the use of technology: findings from the Center for Research and Education on Aging and Technology Enhancement (CREATE). Psychol Aging. 2006;21(2):333-352.

10. Luppa M, Luck T, Weyerer S, Konig HH, Brahler E, Riedel-Heller SG. Prediction of institutionalization in the elderly. A systematic review. Age Ageing. 2010;39(1):31-38.

11. Malinowsky C, Almkvist O, Kottorp A, Nygard L. Ability to manage everyday technology: a comparison of persons with dementia or mild cognitive impairment and older adults without cognitive impairment. Disabil Rehabil Assist Technol. 2010;5(6):462-469.

12. Rosenberg L, Kottorp A, Winblad B, Nygård L. Perceived difficulty in everyday technology use among older adults with or without cognitive deficits. Scand J Occup Ther. 2009;16(4):216-226.

13. Bandura A. Self Efficacy. The Exercise of Control. New York, NY: WH Freeman and Co; 1997.

14. Kobayashi M, Hiyama A, Miura T, Asakawa C, Hirose M, Ifukube T. Elderly user evaluation of mobile touchscreen interactions. Human-Computer Interaction, INTERACT 2011. Human-computer interaction, Lisbon, Portugal 5-9 September, 2011. 2011:83-99.

15. Werner F, Werner K, Oberzaucher J. Tablets for seniors: An evaluation of a current model (iPad). Ambient Assisted Living. 2012:177-184.

16. Bandura A. Guide for constructing self-efficacy scales. In: Pajares F, Urdan T, editors. Self-efficacy Beliefs of Adolescents. Greenwich, CT: IAP; 2006.

17. Folstein MF, Folstein SE, McHugh PR. "Mini-mental state". A practical method for grading the cognitive state of patients for the clinician. J Psychiatr Res. 1975;12(3):189-198.

18. Cohen J. Statistical Power Analysis for the Social Sciences, 2nd ed. Hillsdale, NJ: Lawrence Erlbaum Associates Inc; 1988.

19. Faul F, Erdfeldter E, Lang AG, Buchner A. G*Power 3: A flexible statistical power analysis for the social, behavioral, and biomedical sciences. Behav Res Methods. 2007;39:175-191.

20. Plassman BL, Langa KM, Fisher GG, et al. Prevalence of dementia in the United States: the aging, demographics, and memory study. Neuroepidemiology. 2007;29(1-2):125-132.

21. Koopman-van den Berg DJ, van der Bijl JJ. The use of self-efficacy enhancing methods in diabetes education in the Netherlands. Sch Inq Nurs Pract. 2001;15(3):249-257. 


\section{Publish your work in this journal}

The Journal of Multidisciplinary Healthcare is an international, peerreviewed open-access journal that aims to represent and publish research in healthcare areas delivered by practitioners of different disciplines. This includes studies and reviews conducted by multidisciplinary teams as well as research which evaluates the results or conduct of such teams or

healthcare processes in general. The journal covers a wide range of areas and welcomes submission from practitioners at all levels, from all over the world. The manuscript management system is completely online and includes a very quick and fair peer-review system. Visit http://www.dovepress.com/testimonials.php to read real quotes from published authors.

Submit your manuscript here: http://www.dovepress.com/journal-of-multidisciplinary-healthcare-journal 